\title{
Polymorphisms in the $\mathrm{H} 19$ gene and the risk of lung Cancer among female never smokers in Shenyang, China
}

\author{
Zhihua Yin ${ }^{1}$, Zhigang $\mathrm{Cui}^{2}$, Hang $\mathrm{Li}^{1}$, Juan $\mathrm{Li}^{1}$ and Baosen Zhou ${ }^{1 *}$
}

\begin{abstract}
Background: Long non-coding RNA (IncRNA) H19 is a hot spot in tumor development, progression and metastasis. This study assessed the association between $\mathrm{H} 19$ genetic polymorphisms and the susceptibility of lung cancer.

Methods: The case-control study was conducted to evaluate the association between four selected single nucleotide polymorphisms (rs217727, rs2107425, rs2735469 and rs17658052) in H19 gene and the risk of lung cancer. There were 556 female never smoking lung cancer patients and 395 cancer-free controls. Unconditional logistic regression analysis was used to analyze the associations between four SNPs and lung cancer risks by calculating the odds ratios and their 95\% confidence intervals. The gene-environment interactions were assessed on both additive and multiplicative scales.
\end{abstract}

Results: Compared with carriers carrying homozygous CC genotype, there was a statistically significant increased risk of lung cancer for carriers of the rs $2107425 \Pi$ genotype (odds ratio $=1.599,95 \% \mathrm{Cl}=1.106-2.313, P=0.013$ ). In both dominant and recessive models, significant associations were found between rs 2107425 and lung cancer risk, and the corresponding odds ratios were $1.346(1.022-1.774)$ and $1.400(1.011-1.937)$, with $P$ values 0.035 and 0.043 , respectively. There was no significant correlation between lung cancer risk and rs2735469, rs217727 and rs 17658052 . Interaction analysis showed that their combined effects had a greater impact on lung cancer than individual effects of polymorphism and cooking smoke exposure. However, further analysis showed that the both additive model and the multiplicative model were not statistically significant.

Conclusion: The polymorphism rs2107425 in $\mathrm{H} 19$ gene was associated with the risk of lung cancer among female who never smokes in Shenyang, China.

Keywords: Lung cancer, H19, Single nucleotide polymorphism, Cooking oil fume, Interaction

\section{Background}

Since 1985, lung cancer has been the leading cause of cancer-related deaths worldwide $[1,2]$. According to reports, the incidence and mortality of lung cancer are the highest among various types of cancer in both urban and rural areas of China [3]. Smoking is the most important risk factor for lung cancer. However, global statistics suggest that the cause of lung cancer in 15\% of men and $53 \%$ of women cannot be attributed to smoking [4]. Therefore, other risk factors might also be important

\footnotetext{
* Correspondence: bszhou@cmu.edu.cn

${ }^{1}$ Department of Epidemiology, China Medical University, No. 77, Puhe Road, Shenyang North District, Shenyang 110122, People's Republic of China Full list of author information is available at the end of the article
}

in the development of lung cancer. Despite the wide geographical differences, never-smoking lung cancer patients are more common in women [5]. Therefore, it is urgent to explore the risk factors of lung cancer in female never smokers.

Molecular epidemiological studies play a key role in studying the genes involved in lung cancer. In recent years, molecular mechanisms associated with lung cancer may be revealed by newly developed markers such as non-coding RNAs (ncRNAs). Long noncoding RNAs (lncRNAs), the largest family of non-coding transcripts, play key roles in regulating chromatin dynamics, gene expression, growth, differentiation, and development [6]. lncRNA has been found to be abnormally expressed or

(c) The Author(s). 2018 Open Access This article is distributed under the terms of the Creative Commons Attribution 4.0 International License (http://creativecommons.org/licenses/by/4.0/), which permits unrestricted use, distribution, and 
mutated in cancer in transcriptome studies using next-generation sequencing in recent years [7].

$\mathrm{H} 19$, located in a cluster with the insulin-like growth factor 2 (IGF2) gene on chromosome 11p15.5, is one of the most important lncRNAs. H19 acts as a gene that is up-regulated in hypoxic stress and certain tumors, including lung cancer, and is therefore an indispensable regulator of tumor development [7-12]. Kaplan et al. observe that the expression of H19 in airway epithelial cells in non-smokers is lower than that in smokers [13]. Thereby, the up-regulation of airway epithelial H19 expression can be considered as an early marker of epithelial cell development into lung cancer. Barsyte-Lovejoy et al. have found that the Myc oncogene lead to H19 upregulation by specifically binding to the $\mathrm{H} 19$ promoter region, and also observed the strong relationship between H19 and c-MYC expression levels in lung cancer cells [14].

In recent years, single nucleotide polymorphisms (SNPs) of candidate genes have become the focus of many studies on the genetic susceptibility of cancer. The expression or function of the host lncRNA changes may due to sequence variation of the non-coding RNA gene. Now the researchers conclude that SNPs or mutations in lncRNA sequences may alter expression, and/or influence miRNA binding, and consequently lead to modified cancer risk [6-9]. However, the studies on the association between the SNPs in lncRNAs and the susceptibility of lung cancer are few so far. In this study, we genotyped four tag SNPs of H19 gene (rs217727, rs2107425, rs2735469, and rs17658052) in a case-control study of lung cancer in northeast China. To the best of our knowledge, this is the first study of lung cancer in a never-smoking female population, to assess the impact of SNPs in lncRNA H19 on lung cancer risk.

\section{Methods}

This hospital-based case-control study was carried on in Shenyang City, which is in the northeast of China. The case group includes 556 newly histologically diagnosed lung cancer patients, who are all never smoking females. A total of 395 cancer-free controls is recruited from the medical examination centers and they are also female never smokers and matched to cases by age ( \pm 5 years). Individuals who smoke more than 100 cigarettes in their whole life are defined as smokers, otherwise they are considered as never smokers. Each subject donates $5 \mathrm{ml}$ blood to detect the SNPs and completes a questionnaire including the basic characteristics and the exposure status of environmental factors. The admission of subjects, the epidemiological investigation of environmental factors and detecting of SNPs were performed according to our previous report [15]. Each participant has signed the informed consent form. The study was approved by the Institutional Review Board of the China Medical University.
Genomic DNA samples were obtained using Phenolchloroform Method. Genotyping method of the studied SNPs was introduced in our previous paper [16]. In our previous studies, the significant association between the risk of lung cancer and cooking fume exposure in female never-smokers have been found. Thus, in this study, besides the study of H19 SNPs, we analyzed the interaction between these SNPs and cooking fume exposure on the risk of lung cancer.

The difference of age between cases and controls was assessed by t-test. Hardy-Weinberg equilibrium (HWE) of the genotypes was measured by a goodness-of-fit $x^{2}$ test. The associations between the SNPs and lung cancer risks were analyzed through unconditional logistic regression by calculating the odds ratios (OR) and their 95\% confidence intervals (CI). Both additive model and multiplicative model were used to assess the interaction between the SNPs and cooking fume exposure. The additive interaction was stated through calculating three indicators, which were the relative excess risk due to interaction (RERI), the attributable proportion due to interaction (AP), and the synergy index (S). All of the statistical analyses were two-sided. The statistically significant level was defined as 0.05. The statistical analyses were performed using SPSS software (Version 20.0; IBM SPSS, Inc., Chicago, IL, USA).

\section{Results}

The study was composed of 556 cases and 395 controls, who were all female never smokers in Shenyang, China. The mean ages for cases and controls were 56.74 \pm 11.70 and $56.13 \pm 11.64$ years, with no statistically significant difference $(t=-0.797, P=0.426)$. Of the 556 lung cancer cases, $371(66.7 \%)$ patients were adenocarcinoma, 96 (17.3\%) were squamous cell lung cancer and 89 (16.0\%) were other types. Among the cases and controls, 100 and 66 people had a history of exposure to cooking fumes, respectively, with a statistically significant difference $\left(\mathrm{x}^{2}=\right.$ 9.739, $P=0.002$ ). Individuals exposed to cooking fumes have an increased risk for female never smokers, and the corresponding odds ratio (OR) was $1.804,95 \%$ confidence interval (CI) was 1.243-2.618. The observed genotype frequencies of four polymorphisms (rs217727, rs2107425, rs2735469 and rs17658052) were in agreement with that expected under the Hardy-Weinberg equilibrium in the controls $(P$ values were $0.232,0.513,0.343$ and 0.533 , respectively).

Table 1 shows the relationship between four polymorphisms and lung cancer risks. Compared with CC genotype, rs2107425 TT genotype carriers had a statistically significant increase in lung cancer risk (adjusted OR was $1.599,95 \% \mathrm{CI}=1.106-2.313, P=0.013)$. There were also statistically significant results in both dominant model $(\mathrm{CT}+\mathrm{TT}$ vs $\mathrm{CC})$ and recessive model $(\mathrm{CC}$ vs $\mathrm{CT}+\mathrm{TT})$, 
Table 1 Association between H19 SNPs and lung cancer risks

\begin{tabular}{|c|c|c|c|c|c|c|c|}
\hline $\mathrm{H} 19$ & & Controls (\%) & Cases (\%) & OR $(95 \% \mathrm{Cl})$ & $P$ value & OR $(95 \% \mathrm{Cl})^{*}$ & $P$ value \\
\hline \multirow[t]{7}{*}{ rs217727 } & CC & $165(41.8)$ & 204(36.7) & 1.00 (ref) & & 1.00 (ref) & \\
\hline & CT & $172(43.5)$ & $264(47.5)$ & $1.241(0.937-1.644)$ & 0.132 & $1.247(0.941-1.652)$ & 0.124 \\
\hline & $\pi$ & $58(14.7)$ & $88(15.8)$ & $1.227(0.831-1.812)$ & 0.303 & $1.229(0.832-1.816)$ & 0.300 \\
\hline & $C T+T T$ vs $C C$ & & & $1.238(0.951-1.612)$ & 0.113 & 1.243(0.954-1.618) & 0.107 \\
\hline & TT vs $C T+C C$ & & & $1.093(0.762-1.566)$ & 0.630 & $1.092(0.762-1.565)$ & 0.632 \\
\hline & C allele & $502(63.5)$ & $672(60.4)$ & 1.00 (ref) & & & \\
\hline & T allele & $288(36.5)$ & 440(39.6) & $1.141(0.945-1.378)$ & 0.169 & & \\
\hline \multirow[t]{7}{*}{ rs2107425 } & CC & $140(35.4)$ & 161(29.0) & 1.00 (ref) & & 1.00 (ref) & \\
\hline & CT & 185(46.8) & $266(47.8)$ & $1.250(0.932-1.678)$ & 0.137 & $1.251(0.932-1.678)$ & 0.136 \\
\hline & $\Pi$ & 70(17.7) & $129(23.2)$ & $1.602(1.108-2.317)$ & 0.012 & $1.599(1.106-2.313)$ & 0.013 \\
\hline & $C T+T T$ vs CC & & & $1.347(1.022-1.775)$ & 0.034 & $1.346(1.022-1.774)$ & 0.035 \\
\hline & $C C$ vs $C T+\pi$ & & & $1.403(1.014-1.941)$ & 0.041 & 1.400(1.011-1.937) & 0.043 \\
\hline & C allele & $465(58.8)$ & $588(52.9)$ & 1.00 (ref) & & & \\
\hline & T allele & $325(41.1)$ & $524(47.1)$ & $1.275(1.060-1.533)$ & 0.010 & & \\
\hline \multirow[t]{7}{*}{ rs2735469 } & CC & 359(90.9) & 507(91.2) & 1.00 (ref) & & 1.00 (ref) & \\
\hline & CT & $36(9.1)$ & $46(8.3)$ & $0.905(0.573-1.428)$ & 0.668 & $0.902(0.571-1.425)$ & 0.659 \\
\hline & $\pi$ & $0(0)$ & $3(0.5)$ & $\#$ & $\#$ & $\#$ & $\#$ \\
\hline & $C T+\pi$ vs $C C$ & & & $0.964(0.614-1.513)$ & 0.873 & $0.962(0.613-1.510)$ & 0.866 \\
\hline & TT vs CC + CT & & & $\#$ & $\#$ & $\#$ & $\#$ \\
\hline & C allele & 754(95.4) & 1060(95.3) & 1.00 (ref) & & & \\
\hline & T allele & $36(4.6)$ & $52(4.7)$ & $1.027(0.665-1.588)$ & 0.930 & & \\
\hline \multirow[t]{7}{*}{ rs17658052 } & GG & $371(93.9)$ & $507(91.2)$ & 1.00 (ref) & & 1.00 (ref) & \\
\hline & AG & $24(6.1)$ & $47(8.5)$ & 1.433(0.861-2.386) & 0.166 & $1.419(0.852-2.365)$ & 0.179 \\
\hline & AA & $0(0.0)$ & $2(0.4)$ & $\#$ & $\#$ & $\#$ & \# \\
\hline & $A G+A A$ vs $G G$ & & & $1.494(0.900-2.479)$ & 0.120 & $1.479(0.890-2.455)$ & 0.131 \\
\hline & $A A$ vs $G G+A G$ & & & $\#$ & $\#$ & $\#$ & \# \\
\hline & G allele & 766(97.0) & 1061(95.4) & 1.00 (ref) & & & \\
\hline & A allele & $24(3.0)$ & $51(4.6)$ & $1.534(0.936-2.514)$ & 0.087 & & \\
\hline
\end{tabular}

*: adjusted by age. \#: could not be calculated

and the corresponding ORs $(95 \% \mathrm{CI})$ were $1.346(1.022-$ 1.774) and 1.400 (1.011-1.937), respectively. The $\mathrm{T}$ allele of rs2107425 was suggested to be risk allele of lung cancer $(\mathrm{OR}=1.275,95 \% \mathrm{CI}=1.060-1.533, P=0.010)$. The similar significant associations were also found between rs2107425 with lung adenocarcinoma and squamous cell lung cancer (Table 2). In addition, the rs17658052 AG genotype was found to be significantly associated with an increased risk of squamous cell lung cancer (adjusted OR was $2.411,95 \% \mathrm{CI}=1.175-4.946, P=0.016)$. The A allele of rs17658052 was appeared to be related with the higher risk of squamous cell lung cancer compared with $\mathrm{G}$ allele $(\mathrm{OR}=2.705,95 \% \mathrm{CI}=1.390-5.262, \quad P=0.002)$. However, no significant associations were found for rs217727 and rs2735469 polymorphisms with lung cancer risks (Table 1 and Table 2).
We further explore the combined effects of H19 SNPs and cooking oil fume exposure on lung cancer risk (Table 3 and Table 4). For rs217727 polymorphism, the individuals with both $\mathrm{CT} / \mathrm{TT}$ genotypes (risk genotype) and exposure to cooking oil fumes (risk factor) were more likely to develop lung cancer than those carrying risk genotype but without exposure to cooking fume or with exposure to cooking fume but carrying wild genotype, and the corresponding ORs (95\%CIs) were 2.368 (1.409-3.978), $1.373(0.898-2.098)$ and 1.921 (1.055$3.501)$, respectively. The similar results were also found in rs2107425 and rs2735469 polymorphisms, that was the combination of the risk genotypes of these SNPs and risk factor (cooking oil fume exposure) contributed to a higher risk of lung cancer (Table 3). Since adenocarcinoma is one of the most frequent subtype of lung cancer, 


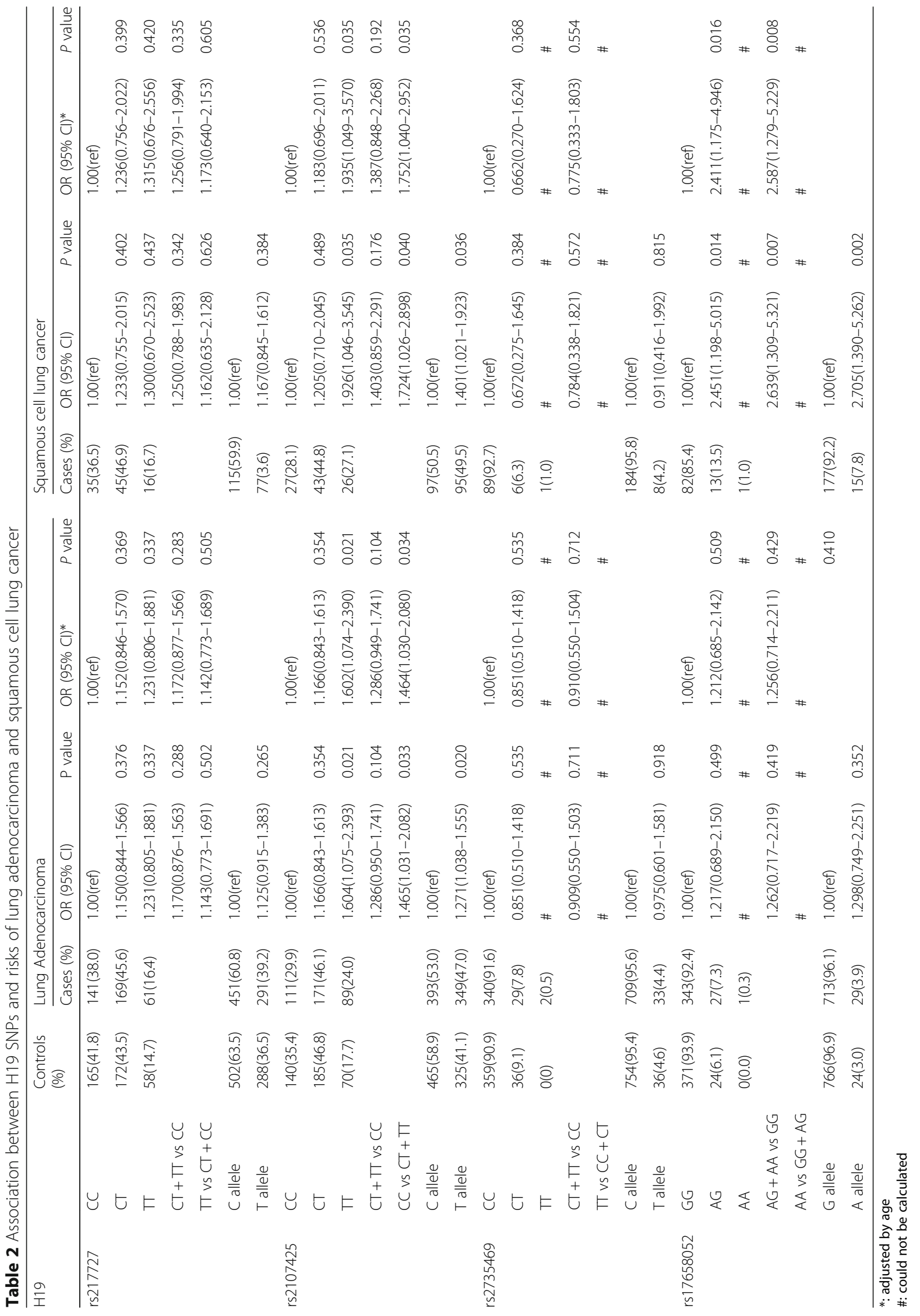


Table 3 Combined effects of H19 SNPs and cooking oil fume exposure on lung cancer risk

\begin{tabular}{|c|c|c|c|c|c|c|}
\hline \multicolumn{2}{|l|}{ SNP } & \multirow{2}{*}{$\begin{array}{l}\text { Oil } \\
\text { Non-exposure }\end{array}$} & \multirow{2}{*}{$\begin{array}{l}\text { Controls (\%) } \\
86(32.3)\end{array}$} & \multirow{2}{*}{$\begin{array}{l}\text { Cases (\%) } \\
59(22.0)\end{array}$} & \multirow{2}{*}{$\begin{array}{l}\text { OR }(95 \% \mathrm{Cl})^{*} \\
1 \text { (ref) }\end{array}$} & \multirow[t]{2}{*}{$P$ value } \\
\hline rs217727 & $\mathrm{CC}$ & & & & & \\
\hline & $C T+T$ & Non-exposure & $114(42.9)$ & 109(40.7) & $1.373(0.898-2.098)$ & 0.143 \\
\hline & CC & Exposure & $27(10.2)$ & $36(13.4)$ & $1.921(1.055-3.501)$ & 0.033 \\
\hline & $\mathrm{CT}+\mathrm{TT}$ & Exposure & $39(14.6)$ & $64(23.9)$ & $2.368(1.409-3.978)$ & 0.001 \\
\hline \multirow[t]{4}{*}{ rs2107425 } & CC & Non-exposure & $70(26.3)$ & $43(16.0)$ & 1 (ref) & \\
\hline & $\mathrm{CT}+\mathrm{TT}$ & Non-exposure & 130(48.9) & 125(46.6) & $1.550(0.985-2.439)$ & 0.058 \\
\hline & $\mathrm{CC}$ & Exposure & $25(9.4)$ & 29(10.8) & $1.852(0.960-3.575)$ & 0.066 \\
\hline & $C T+\pi$ & Exposure & $41(15.4)$ & $71(26.5)$ & $2.811(1.636-4.830)$ & $<0.001$ \\
\hline \multirow[t]{4}{*}{ rs2735469 } & $C T+\pi$ & Non-exposure & $18(6.8)$ & $10(3.7)$ & 1 (ref) & \\
\hline & CC & Non-exposure & 182(68.4) & 158(59.0) & $1.548(0.693-3.455)$ & 0.286 \\
\hline & $\mathrm{CT}+\mathrm{TT}$ & Exposure & $9(3.4)$ & $7(2.6)$ & $1.388(0.395-4.876)$ & 0.609 \\
\hline & CC & Exposure & $57(21.4)$ & 93(34.7) & $2.906(1.253-6.744)$ & 0.013 \\
\hline \multirow[t]{4}{*}{ rs17658052 } & GG & Non-exposure & 188(70.7) & 150(56.0) & 1 (ref) & \\
\hline & $\mathrm{GA}+\mathrm{AA}$ & Non-exposure & $12(4.5)$ & $18(6.7)$ & $1.900(0.887-4.073)$ & 0.099 \\
\hline & GG & Exposure & $62(23.3)$ & $94(35.1)$ & $1.897(1.289-2.792)$ & 0.001 \\
\hline & $\mathrm{GA}+\mathrm{AA}$ & Exposure & $4(1.5)$ & $6(2.2)$ & $1.920(0.531-6.948)$ & 0.320 \\
\hline
\end{tabular}

*: adjusted by age

with a higher incidence in women, we analyzed the combined effects of the SNPs in H19 gene and cooking oil fume exposure on lung adenocarcinoma susceptibility among female never smokers in Shenyang, China (Table 4). The combination of the risk genotype and exposure to cooking fume lead to a higher risk of lung adenocarcinoma than the individual effect of either risk genotype or exposure to cooking fume, suggesting that there may be interaction between these SNPs and cooking fume exposure, so we further explored the interaction on both additive and multiplicative scales through quantitative and statistically significant analysis (shown in Table 5).

Table 5 showed the additive measures of biological interaction between SNPs in H19 gene and cooking fume exposure on lung cancer in never-smoking women

Table 4 Combined effects of H19 SNPs and cooking oil fume exposure on lung adenocarcinoma risk

\begin{tabular}{|c|c|c|c|c|c|c|}
\hline SNP & & Oil & Controls (\%) & Cases (\%) & OR $(95 \% \mathrm{Cl})^{*}$ & $P$ value \\
\hline \multirow[t]{4}{*}{ rs217727 } & $\mathrm{CC}$ & Non-exposure & $86(32.3)$ & $49(24.9)$ & 1 (ref) & \\
\hline & $C T+\pi$ & Non-exposure & $114(42.9)$ & 77 (39.1) & $1.180(0.748-1.859)$ & 0.477 \\
\hline & CC & Exposure & $27(10.2)$ & 23(11.7) & $1.480(0.766-2.859)$ & 0.243 \\
\hline & $C T+\pi$ & Exposure & $39(14.6)$ & $48(24.4)$ & $2.147(1.239-3.721)$ & 0.006 \\
\hline \multirow[t]{4}{*}{ rs2107425 } & CC & Non-exposure & $70(26.3)$ & $36(18.3)$ & 1 (ref) & \\
\hline & $\mathrm{CT}+\mathrm{T}$ & Non-exposure & $130(48.9)$ & $90(45.7)$ & $1.342(0.827-2.177)$ & 0.233 \\
\hline & CC & Exposure & $25(9.4)$ & $21(10.7)$ & $1.614(0.796-3.273)$ & 0.184 \\
\hline & $C T+\pi$ & Exposure & $41(15.4)$ & $50(25.4)$ & $2.362(1.327-4.204)$ & 0.003 \\
\hline \multirow[t]{4}{*}{ rs 2735469} & $C T+T$ & Non-exposure & $18(6.8)$ & $7(3.6)$ & 1 (ref) & \\
\hline & $\mathrm{CC}$ & Non-exposure & $182(68.4)$ & 119(60.4) & $1.679(0.680-4.145)$ & 0.261 \\
\hline & $C T+\pi$ & Exposure & $9(3.4)$ & $6(3.0)$ & $1.697(0.438-6.570)$ & 0.444 \\
\hline & $\mathrm{CC}$ & Exposure & $57(21.4)$ & $65(33.0)$ & $2.917(1.136-7.492)$ & 0.026 \\
\hline \multirow[t]{4}{*}{ rs17658052 } & GG & Non-exposure & 188(70.7) & $114(57.9)$ & 1 (ref) & \\
\hline & $\mathrm{GA}+\mathrm{GG}$ & Non-exposure & $12(4.5)$ & $12(6.1)$ & $1.647(0.716-3.791)$ & 0.241 \\
\hline & GG & Exposure & $62(23.3)$ & $68(34.5)$ & $1.798(1.186-2.725)$ & 0.006 \\
\hline & $\mathrm{GA}+\mathrm{AA}$ & Exposure & $4(1.5)$ & $3(1.5)$ & $1.268(0.278-5.781)$ & 0.759 \\
\hline
\end{tabular}


Table $\mathbf{5}$ Measures of additive interaction between H19 SNPS and cooking oil fume exposure

\begin{tabular}{lllllll}
\hline SNP & Measure & \multicolumn{2}{l}{ Lung cancer } & & \multicolumn{2}{c}{ Lung adenocarcinoma } \\
\cline { 3 - 4 } & & Estimate & $95 \% \mathrm{Cl}$ & & Estimate & $95 \% \mathrm{Cl}$ \\
\hline rs217727 & RERI & 0.074 & $-1.354-1.502$ & 0.488 & $-0.797-1.773$ \\
& AP & 0.031 & $-0.566-0.628$ & 0.227 & $-0.326-0.780$ \\
& S & 1.057 & $0.357-3.129$ & 1.740 & $0.305-9.926$ \\
rs2107425 & RERI & 0.409 & $-1.127-1.944$ & 0.405 & $-1.016-1.826$ \\
& AP & 0.145 & $-0.374-0.665$ & 0.172 & $-0.401-0.744$ \\
& S & 1.291 & $0.465-3.589$ & 1.424 & $0.357-5.683$ \\
rs2735469 & RERI & 0.970 & $-0.738-2.679$ & 0.541 & $-1.573-2.654$ \\
& AP & 0.334 & $-0.262-0.930$ & 0.185 & $-0.588-0.929$ \\
& S & 2.037 & $0.270-15.387$ & 1.393 & $0.273-7.113$ \\
rs17658052 & RERI & -0.877 & $-3.773-2.020$ & -1.177 & $-3.626-1.272$ \\
& AP & -0.456 & $-2.468-1.555$ & -0.928 & $-4.045-2.189$ \\
& S & 0.512 & $0.032-8.226$ & 0.1864 & $0.000-244.516$ \\
\hline
\end{tabular}

of China. There are three measures of additive interaction as well as their confidence intervals. All measurements showed no significant interactions between the four SNPs and exposure to cooking fumes on the additive scale. Otherwise, based on logistic regression results, the gene-environment interactions on the multiplicative scale were not statistically significant $(P$ values were 0.665 , $0.928,0.897$ and 0.473 for rs217727, rs2107425, rs2735469 and rs17658052 in lung cancer, and 0.888, 0.903, 0.773 and 0.312 in lung adenocarcinoma).

To further investigate the relationship between H19 and cancer development, we summarized the effects of H19 on malignant phenotypes (including proliferation, differentiation, invasion, metastasis, and invasion) and its molecular mechanisms (see Additional file 1: Table $\mathrm{S} 1)$. In addition, $\mathrm{H} 19$ has a variety of molecular functions, including transcriptional dyregulation, pre-mRNA alternative splicing, ceRNA role, epigenetic alterations and transition of cell phenotype through different signaling pathways covering EMT, Wnt and other pathways. Taken together, H19 exerted its molecular function in order to regulate the expression of related genes, which may affect carcinogenic signaling pathways, thereby promoting the progression of malignant carcinoma.

\section{Discussion}

To the best of our knowledge, this study initiated the first survey to test associations between H19 polymorphisms (rs2107425, rs217727, rs2735469 and rs17658052) and lung cancer susceptibility, as well as the interactions between these polymorphisms and cooking oil fume exposure among female never smokers in Shenyang, China. The homozygous variant genotype of rs2107425 was thought to be associated with an increased risk of lung cancer. The individual effects of both SNP and cooking smoke exposure were much smaller than their combined effect on lung cancer. However, further analysis showed that the interactions on both additive and multiplicative models were not statistically significant.

Up to the present, some studies have shown the relationship between H19 polymorphisms and several types of cancer. Xia et al. indicated that there was a strong relationship between H19 polymorphisms (rs3741219 and rs217727) and the susceptibility of breast cancer in stratified analyses [17]. Another study found that the risk of bladder cancer in rs217727 AA genotype carriers was statistically significant increased compared with GG/GA genotype carriers [18]. Verhaegh et al. have found that H19 genetic polymorphisms (rs2839698 and rs2107425) might be associated with the susceptibility of bladder cancer in European Caucasians [19]. In the present study, we selected four common SNPs (rs217727, rs2107425, rs2735469, and rs17658052) in H19 gene to estimate the association between these variants and lung cancer susceptibility. We observe that rs 2107425 polymorphism may be able to influence the risk of lung cancer in Chinese female never smokers. All of these suggested that H19 genetic variants might have an important effect on cancer susceptibility. However, to validate this conclusion, the researches in different ethnicities and the functional experiments are urgently needed.

$\mathrm{H} 19$, located in chromosome $11 \mathrm{p} 15.5$, is a paternally imprinted oncofetal lncRNA gene with oncogenic properties [20]. Previous studies have indicated the complex biological process of oncogenesis involves the participation of H19 [21, 22]. Jiang et al. showed that the invasion, angiogenesis, stemness, and tumorigenicity of glioblastoma cells were promoted by the increased expression of H19 lncRNA [23]. Despite the accumulation of evidence, the role of H19 in the molecular mechanism of tumorigenesis is still unclear. Evidence of genetic variants in lncRNAs that modified the risk of tumors continued to emerge $[24,25]$. In addition, multiple SNPs have been identified associated with cancer susceptibility by genome-wide association studies (GWASs). However, there still have some limits in the clarification of causal SNPs and the deep mining of GWAS data. In recent years, these have attracted the attention of researchers [26-28]. In the present study, the association between H19 polymorphisms and lung cancer susceptibility was analyzed based on our previous GWAS results. Ultimately, we need sophisticated experimental design and implementation in order to not only further reveal the mystery of lncRNA but also effectively address diagnostic/prognostic biomarkers and therapeutic targets for cancer.

Indeed, lncRNAs may have crucial roles in some important aspects such as drug response and toxicity. Previous studies have shown that these two SNPs were 
involved in platinum-based chemotherapy responses in lung cancer. Gong et al. indicated that H19 rs2839698 had a relationship with platinum-based chemotherapy response, and H19 rs2107425 was associated with platinum-based chemotherapy response in patients with small cell lung cancer [29]. We found that H19 rs2107425 and rs2839698 were associated with severe gastrointestinal toxicity, and rs2839698 in lung cancer patients with severe hematologic toxicity have accepted GP regimen [30]. The report also showed that there was a significant association between overexpression of H19 and the poor survival of lung cancer patients [31].

A known risk factor of lung cancer is cigarette smoking. However, the public and researchers need to be aware of the impact of other environmental risk factors on lung cancer. The epidemiologic characteristics of lung cancer in Chinese women have been discovered by the researchers, that is, they smoke very little but have lung cancer is relatively frequent, so the epidemiologic characteristics of lung cancer cannot be fully explained by cigarette smoking. In this sense, the ideal subjects for detecting unknown factors in lung cancer are the females who never smoke. In order to examine risk factors and genetic susceptibility of lung cancer in Chinese never-smoking females, our research team has been devoting themselves. In previous studies, the associations between cooking oil fume exposure and lung cancer risk women who never smoke have been noted. In the present study, so as to obtain some clues about the biological role that the gene-environment interaction played in the development of lung cancer, the interaction of both IncRNA H19 SNPs and cooking oil fume with the susceptibility of lung cancer was evaluated. However, we found that the interactions of four SNPs and cooking oil fume exposure were not statistically significant through the statistical analysis on both additive scale and multiplicative scale.

There are several limitations of the present research. First, since all subjects were recruited from the hospitals, we cannot avoid selection bias. Second, when collecting demographic data, some risk factors associated with the case group may be taken by the investigators, such as the status of cooking oil fume, which as far as known are associated with the case group while in a manner that is incomparable to the control group. Finally, since all subjects of our study are limited to Chinese never-smoking females, the sample size is not very large. In future study, so as to verify the conclusion in different races, we need a larger population of lung cancer. For the present result is just a statistical estimation, the biological validity of lncRNA and their SNPs are required in further functional studies.

In summary, this study showed that the single nucleotide polymorphisms in $\mathrm{H} 19$ gene might play vital roles in lung cancer development. There is a positive significance in our study to explore the pathogenesis of lung cancer, and to some degree, provide clues for diagnostic biomarkers and therapeutic targets of lung cancer in future.

\section{Conclusion}

The polymorphism rs2107425 in H19 gene is associated with the risk of lung cancer among female never smokers in Shenyang, China.

\section{Additional file}

Additional file 1: Table S1. Research advances of $\mathrm{H} 19$ roles in human cancers (indicates increase; indicates decrease). (DOCX 239 kb)

\section{Abbreviations}

AP: The attributable proportion due to interaction; Cl: Confidence interval; GWAS: Genome-wide association study; IncRNA: Long non-coding RNA OR: Odds ratio; RERI: The relative excess risk due to interaction; S: The synergy index; SNP: Single nucleotide polymorphism

\section{Acknowledgements}

We are grateful to patients for their participation. We would like to thank all the personnel at the hospitals in our study.

\section{Funding}

This study was supported by Program for Innovation Talents in Universities of Liaoning Province (No. LR2016026). Funding bodies have no role in the study design, study setting, analysis, or writing of the manuscript.

\section{Availability of data and materials}

The datasets during and/or analyzed during the current study available from the corresponding author on reasonable request.

\section{Authors' contributions}

$Y Z$ and $C Z$ collected the data. $Y Z$ and $L H$ analyzed the data. $Y Z, C Z$ and $L$ wrote the main manuscript text. ZB conceived the study and managed communication during the subjects' collection. All authors reviewed the manuscript.

Ethics approval and consent to participate

The study was approved by the Institutional Review Board of China Medical University and written informed consent was obtained from each participant.

Consent for publication

Not applicable.

Competing interests

The authors declare that they have no competing interests.

\section{Publisher's Note}

Springer Nature remains neutral with regard to jurisdictional claims in published maps and institutional affiliations.

\section{Author details}

'Department of Epidemiology, China Medical University, No. 77, Puhe Road, Shenyang North District, Shenyang 110122, People's Republic of China.

${ }^{2}$ School of Nursing, China Medical University, Shenyang 110122, People's Republic of China. 
Received: 30 October 2017 Accepted: 4 September 2018 Published online: 15 September 2018

\section{References}

1. Parkin D, Pisani P, Ferlay J. Estimates of the worldwide incidence of eighteen major cancers in 1985. Int J Cancer. 1993;54:594-606.

2. Torre LA, Bray F, Siegel RL, Ferlay J, Lortet-Tieulent J, Jemal A. Global cancer statistics, 2012. CA Cancer J Clin. 2015;65:87-108.

3. Chen W, Zheng R, Zeng H, Zhang S, He J. Annual report on status of cancer in China, 2011. Chin J Cancer Res. 2015;27:2-12.

4. Parkin DM, Bray F, Ferlay J, Pisani P. Global cancer statistics, 2002. CA Cancer J Clin. 2005;55:74-108.

5. Couraud S, Zalcman G, Milleron B, Morin F, Souquet PJ. Lung cancer in never smokers--a review. Eur J Cancer. 2012;48:1299-311.

6. Bhan A, Soleimani M, Mandal SS. Long noncoding RNA and Cancer: a new paradigm. Cancer Res. 2017;77:3965-81.

7. Bhan A, Mandal SS. Long noncoding RNAs: emerging stars in gene regulation, epigenetics and human disease. Chem Med Chem. 2014;9:1932-56.

8. Cui J, Mo J, Luo M, Yu Q, Zhou S, Li T, et al. c-Myc-activated long noncoding RNA H19 downregulates miR-107 and promotes cell cycle progression of non-small cell lung cancer. Int J Clin Exp Pathol. 2015;8: 12400-9.

9. Kondo M, Suzuki H, Ueda R, Osada H, Takagi K, Takahashi T, et al. Frequent loss of imprinting of the $\mathrm{H} 19$ gene is often associated with its over expression in human lung cancers. Oncogene. 1995;10:1193-8.

10. Yang F, Bi J, Xue X Zheng L, Zhi K, Hua J, et al. Up-regulated long noncoding RNA H19 contributes to proliferation of gastric cancer cells. FEBS J. 2012;279:3159-65.

11. Ariel I, Sughayer M, Fellig Y, Pizov G, Ayesh S, Podeh D, et al. The imprinted $\mathrm{H} 19$ gene is a marker of early recurrence in human bladder carcinoma. Mol Pathol. 2000;53:320-3.

12. Lottin S, Adriaenssens E, Dupressoir T, Berteaux N, Montpellier C, Coll J, et al. Overexpression of an ectopic $\mathrm{H} 19$ gene enhances the tumorigenic properties of breast cancer cells. Carcinogenesis. 2002;23:1885-95.

13. Kaplan R, Luettich K, Heguy A, Hackett NR, Harvey BG, Crystal RG. Monoallelic up-regulation of the imprinted $\mathrm{H} 19$ gene in airway epithelium of phenotypically normal cigarette smokers. Cancer Res. 2003;63:1475-82.

14. Barsyte-Lovejoy D, Lau SK, Boutros PC, Khosravi F, Jurisica I, Andrulis IL, et al. The c-Myc oncogene directly induces the H19 noncoding RNA by allelespecific binding to potentiate tumorigenesis. Cancer Res. 2006;66:5330-7.

15. Yin Z, Cui Z, Li H, Ren Y, Qian B, Rothman N, Lan Q, Zhou B. Polymorphisms in miR-135a-2, miR-219-2 and miR-211 as well as their interaction with cooking oil fume exposure on the risk of lung cancer in Chinese nonsmoking females: a case-control study. BMC Cancer. 2016;16:751.

16. Lan Q, Hsiung CA, Matsuo K, Hong YC, Seow A, Wang Z, et al. Genomewide association analysis identifies new lung cancer susceptibility loci in never-smoking women in Asia. Nat Genet. 2012:44:1330-5.

17. Xia Z, Yan R, Duan F, Song C, Wang P, Wang K. Genetic polymorphisms in long noncoding RNA H19 are associated with susceptibility to breast Cancer in Chinese population. Medicine (Baltimore). 2016;95(7):e2771.

18. Hua Q, Lv X, Gu X, Chen Y, Chu H, Du M, et al. Genetic variants in IncRNA $\mathrm{H} 19$ are associated with the risk of bladder cancer in a Chinese population. Mutagenesis. 2016;31(5):531-8.

19. Verhaegh GW, Verkleij L, Vermeulen SH, den Heijer M, Witjes JA, Kiemeney $\mathrm{LA}$. Polymorphisms in the $\mathrm{H} 19$ gene and the risk of bladder cancer. Eur Urol. 2008;54:1118-26.

20. Gabory A, Ripoche MA, Yoshimizu T, Dandolo L. The H19 gene: regulation and function of a non-coding RNA. Cytogenet Genome Res. 2006;113:188-93.

21. Matouk IJ, Halle D, Raveh E, Gilon M, Sorin V, Hochberg A. The role of the oncofetal H19 IncRNA in tumor metastasis: orchestrating the EMT-MET decision. Oncotarget. 2016;7:3748-65.

22. Kallen AN, Zhou XB, Xu J Qiao C, Ma J, Yan L, et al. The imprinted H19 IncRNA antagonizes let-7 microRNAs. Mol Cell. 2013;52:101-12.

23. Jiang $X$, Yan $Y$, Hu M, Chen $X$, Wang $Y$, Dai $Y$, et al. Increased level of H19 long noncoding RNA promotes invasion, angiogenesis, and stemness of glioblastoma cells. J Neurosurg. 2016;124(1):129-36.

24. Gong J, Tian J, Lou J, Ke J, Li L, Li J, Yang Y, Gong Y, Zhu Y, Zhang Y, Zhong R, Chang J, Miao X. A functional polymorphism in InC-LAMC2-1:1 confers risk of colorectal cancer by affecting miRNA binding. Carcinogenesis. 2016; 37(5):443-51.
25. Wen J, Liu Y, Liu J, Liu L, Song C, Han J, Zhu L, Wang C, Chen J, Zhai X, Shen $\mathrm{H}, \mathrm{Hu} \mathrm{Z}$. Expression quantitative trait loci in long non-coding RNA ZNRD1-AS1 influence both HBV infection and hepatocellular carcinoma development. Mol Carcinog. 2015;54(11):1275-82.

26. Zheng J, Huang X, Tan W, Yu D, Du Z, Chang J, Wei L, Han Y, Wang C, Che $X$, Zhou Y, Miao X, Jiang G, Yu X, Yang X, Cao G, Zuo C, Li Z, Wang C, Cheung ST, Jia $Y$, Zheng $X$, Shen $H$, Wu C, Lin D. Pancreatic cancer risk variant in LINC00673 creates a miR-1231 binding site and interferes with PTPN11 degradation. Nat Genet. 2016;48(7):747-57.

27. Li J, Zou L, Zhou Y, Li L, Zhu Y, Yang Y, Gong Y, Lou J, Ke J, Zhang Y, Tian J, Zou D, Peng X, Chang J, Gong J, Zhong R, Zhou X, Miao X. A low-frequency variant in SMAD7 modulates TGF- $\beta$ signaling and confers risk for colorectal cancer in Chinese population. Mol Carcinog. 2017;56(7):1798-807.

28. Lou J, Gong J, Ke J, Tian J, Zhang Y, Li J, Yang Y, Zhu Y, Gong Y, Li L, Chang J, Zhong R, Miao X. A functional polymorphism located at transcription factor binding sites, rs6695837 near LAMC1 gene, confers risk of colorectal cancer in Chinese populations. Carcinogenesis. 2017;38(2):177-83.

29. Gong WJ, Yin JY, Li XP, Fang C, Xiao D, Zhang W, et al. Association of wellcharacterized lung cancer IncRNA polymorphisms with lung cancer susceptibility and platinum-based chemotherapy response. Tumour Biol. 2016;37(6):8349-58.

30. Gong WJ, Peng JB, Yin JY, Li XP, Zheng W, Xiao L. Association between well-characterized lung cancer IncRNA polymorphisms and platinum-based chemotherapy toxicity in Chinese patients with lung cancer. Acta Pharmacol Sin. 2017;38(4):581-90.

31. Chen B, Yu M, Chang Q, Lu Y, Thakur C, Ma D, et al. Mdig derepresses H19 large intergenic non-coding RNA (lincRNA) by downregulating H3K9me3 and heterochromatin. Oncotarget. 2013;4:1427-37.

\section{Ready to submit your research? Choose BMC and benefit from:}

- fast, convenient online submission

- thorough peer review by experienced researchers in your field

- rapid publication on acceptance

- support for research data, including large and complex data types

- gold Open Access which fosters wider collaboration and increased citations

- maximum visibility for your research: over $100 \mathrm{M}$ website views per year

At BMC, research is always in progress.

Learn more biomedcentral.com/submissions 